\title{
COMBINED EFFECT OF COMPOSITION AND SURFACE CONDITION ON CORROSION BEHAVIOUR OF MAGNESIUM ALLOYS AZ31 AND AZ61
}

Alejandro Samaniego ${ }^{a}$, Irene Llorente ${ }^{a}$ and Sebastián Feliu (Jr) ${ }^{a}$.

Centro Nacional de Investigaciones Metalúrgicas CSIC, Avda. Gregorio del Amo 8, 28040 Madrid, Spain, (e-mail: sfeliu@cenim.csic.es).

Corresponding author: Tel.:+34 91 5538900. Fax. +34 91 5347425. Email address: sfeliu@cenim.csic.es

\begin{abstract}
This work is an attempt to learn more about the role of several experimental variables in the corrosion behaviour of magnesium alloys in immersion tests carried out in $0.6 \mathrm{M} \mathrm{NaCl}$. In particular, the study has considered the effect of as-received and polished surface conditions, geometrical characteristics of the exposed area, and different aluminium contents in the magnesium based alloys. Special attention has been paid to the three forms of attack normally found in this research. In addition to the morphology of attack, the effect of the tested variables on the corrosion rate of the specimens has also been investigated.
\end{abstract}

Keywords: A. Magnesium; A. Alloy; B Weight loss; C. Pitting corrosion 


\section{Introduction}

As can be seen in the literature, different studies on the corrosion of magnesium alloys in apparently similar experimental circumstances may yield unequal results [1]. This casts doubts as to the true meaning of certain results, which could be clarified by means of a knowledge of the factors that influence them and their relative importance.

In several studies[2-8] it has become apparent the effect of certain combinations of variables, relating to specimen preparation and testing conditions, on the results obtained. The purpose of the present work has been to gain a better understanding of the influence of surface condition and specimen configuration variables on the corrosion behaviour of AZ31 and AZ61 magnesium based alloys in immersion corrosion tests carried out in $0.6 \mathrm{M} \mathrm{NaCl}$ solution. It is well known that the presence of chloride ion promotes the corrosion of magnesium alloys in aqueous solutions; a relatively high chloride concentration has been selected in order to accentuate possible effects.

Specifically, this study addresses the effect on the attack morphology and corrosion rate of AZ31 and AZ61 alloys of the: (a) configuration of the exposed surface area of the specimens; (b) surface condition at the start of the test; and (c) a change in the metallic composition using the two aforementioned commercial magnesium-aluminium alloys. In (a), special attention has been paid to the possible repercussion of the confinement of the exposed area by means of a circular plastic gasket and to the presence of cut edges on the square coupon specimens entirely exposed to the aggressive solution. Depending on the special circumstances of each case, examination of the corroded surfaces has shown substantially varied morphologies, which include 
uniform corrosion, filiform corrosion, and localised attack with the formation of pits and cavities.

\section{Experimental}

\subsection{Materials}

The chemical composition of the tested AZ31 and AZ61 magnesium alloys is given in Table 1. These alloys were manufactured in wrought condition and supplied in $3 \mathrm{~mm}$ thick plates by Magnesium Elecktron Ltd.

\subsection{Surface conditions}

The research compares the behaviour of specimens of the above alloys in the following two surface conditions: (a) specimens in as-received condition; and (b) freshly polished specimens. In the as-received condition, the untreated surfaces were only cleaned with distilled water and dried with hot air. As these are commercial materials, precise information is not available on the various stages of their manufacturing, in particular about heat treatment and hot rolling operations with a probable influence on the as-received surface properties. For obtaining the freshly polished condition, the specimens were dry ground through successive grades of silicon carbide abrasive paper, from P600 to P2000, followed by finishing with 3 and $1 \mu \mathrm{m}$ diamond paste, cleaned in distilled water and dried with hot air.

The difference between as-received and polished surfaces has been clearly evident in the roughness measurements carried out using atomic force microscopy (AFM). The as-received surfaces of alloys AZ31 and AZ61 yielded the highest roughness values, 198 and $116 \mathrm{~nm}$ RMS (root mean value), 
respectively, while the corresponding values for the polished surfaces were only 29 and 17 nn RMS.

\subsection{Corrosion testing}

The corrosion rate of the specimens was monitored by measuring the volume of hydrogen evolved during the experiments. Hydrogen was collected in a burette above the corroding sample using a similar procedure to that described in the literature[7,8]. Corrosion weight loss rates were estimated from the hydrogen evolution data[1].

\subsection{Specimen configuration}

In general, square coupon specimens, with dimensions of $2 \mathrm{~cm} \times 2 \mathrm{~cm} \times 0.3$ $\mathrm{cm}$, have been used. All or part of the specimen surface has been exposed to the corrosion test. In the latter case the different configurations were: (i) specimens with a free surface area of $0.5,0.8$ or $9,0 \mathrm{~cm}^{2}$, defined by the inner diameter of a circular plastic gasket (Fig. 1); (ii) specimens with one of its two faces masked with epoxy resin; and (iii) specimens with a hole $0.3 \mathrm{~cm}$ in diameter drilled through them.

Tested specimens were suspended vertically in the $0.6 \mathrm{~m} \mathrm{NaCl}$ solution and others were exposed in horizontal position.

\subsection{Corrosion morphology observations}

The attack morphology on the corroded surface was examined at low magnification. Photographic images were taken with an optical zoom camera. 


\section{RESULTS}

\subsection{Morphology of the corroded surfaces}

In this research, repeated tests have been carried out in order to analyse the corrosion attack morphologies developed on the 130 specimens that reasonably represented the effect of the different variables taken into consideration. These specimens belong proportionately to alloys $A Z 31$ and AZ61 and to the asreceived and polished surface conditions.

Particular attention has been paid to the three forms of corrosion ordinarily found in this research: uniform corrosion, localised corrosion and filiform corrosion. The latter term is applied when the dark thread-like filaments that characterise this type of morphology are clearly perceived. Filiform corrosion is usually initiated at different points on the metallic surface, and, at a rate which depends on the alloy type and surface preparation, gradually becomes converted into a dense mesh of indiscernible filaments. When this occurs, the attack morphology becomes confused with that of uniform corrosion and is classified under this heading.

Macroscopic examination of the corroded specimens has often shown the presence of filiform-like attack together with areas of uniform corrosion. Localised forms of attack have been less abundant, but can nevertheless be observed at microscopic scale, as in Fig. 2, this revealing a large number of small pits of less than one micron diameter, or Fig. 3, with series of pits distributed on the filament grooves left on the corroded surface.

Full information on the combined effect of alloy type and surface condition is summarised below. The following nomenclature is used in the remainder of the 
paper to designate the four dual combinations tested: AZ31-O, AZ31-P, AZ61$\mathrm{O}$, and AZ61-P, where the letters $\mathrm{O}$ and $\mathrm{P}$, that accompany the alloy type, denote: $\mathrm{O}=$ original surface condition (e.g., as-received condition); $\mathrm{P}=$ polished surface condition. The tested specimens normally exposed an area of 9 to 14 $\mathrm{cm}^{2}$ to the corrosive solution, while the specimens labelled "small exposed area" exposed an area of 0.5 to $0.8 \mathrm{~cm}^{2}$ limited by a circular gasket on the flat surface.

In general, the following trends have been disclosed when examining the attack morphologies on the specimens exposed to the $0.6 \mathrm{M} \mathrm{NaCl}$ solution:

AZ31-O: Predominance of uniform attack on all the exposed surface with possible signs of filiform corrosion on some specimens. In the case of the small exposed area, uniform attack is accompanied by pitting or cavities that occupy part of the surface. A typical example of this morphology is shown in Fig. 4.

AZ31-P: Large areas of uniform attack with the occurrence of filiform corrosion close to the shear cut specimen edges and the drilled hole. This morphology can be seen in Fig. 5. In the case of the small exposed area, attention is drawn to the abundance of pits and some larger cavities in the central zone of the exposed surface.

AZ61-O: Uniform attack and areas of filiform corrosion close to the specimen edges which can occupy $30-60 \%$ of the exposed surface. In the case of the small exposed area, numerous pits and some larger cavities in the central zone of the exposed surface.

AZ61-P: Uniform attack on a large part of the exposed surface. In parallel, occurrence of filiform corrosion, generally initiated at the cut specimen edges 
(e.g. morphology in Fig. 6). In the case of the small exposed area, variety of localised forms, including pitting and some open cavities.

The visual evolution of the corrosion morphology of alloys AZ31 and AZ61 with immersion time is well illustrated in the series of photographs displayed in Fig. 7 for specimens immersed horizontally about $50 \mathrm{~mm}$ below the surface of the test solution, obtained with a photographic camera mounted above the solution. On the AZ31 alloy, filiform corrosion is initiated almost immediately after immersion, especially on the as-received surface; the population of filaments expands in less than one day across the entire exposed surface. On the AZ61 alloy, the initiation and evolution of filiform corrosion is significantly slower than on AZ31, and clusters of propagating filaments do not appear until after $19 \mathrm{~h}$ of immersion on the as-received surface or $70 \mathrm{~h}$ on the polished surface. With increasing immersion time, expansion and densification of the mesh of filaments causes the corroding surface of both alloys to become darker and to take on the apperance of uniform corrosion, a development that occurs much faster with alloy AZ31 than with AZ61.

In Fig. 7 it is curious to see that after relatively long immersion times -around $200 \mathrm{~h}$ for alloy AZ31 in as-received surface condition and around $43 \mathrm{~h}$ for the polished condition- the formation of filiform corrosion clusters recommences, these differing from those initially formed by the greater thickness of the filaments and the almost nil tendency to expand and evolve with time. 


\section{DISCUSSION}

The triggering and degree of activity of the corrosion processes that take place on the metallic surface is normally related with defect sites present in the oxide film that covers the surface, which can be stimulated by the adsorption of chloride ions in a saline medium and by the difference in potential between bore exposed alloy ( in the defects) and the neighbouring oxide film. Microstructural features often promote the formation of points of attack due to the discontinuities that they cause in the oxide film. In alloy AZ61 the aluminium is partly precipitated in the form of $\beta$-phase, preferentially along the grain boundaries, and so this second phase can cause micro-galvanic corrosion acceleration of the $\alpha-M g$ matrix $[9,10]$. In contrast, this effect is irrelevant in the alloy AZ31 due to its lower Al content and practically nil presence of $\beta$-phase. As will be seen later, galvanic corrosion can explain some of the differences in the corrosion rates of the tested specimens.

On the square specimens, whose entire surface $\left(\sim 9-14 \mathrm{~cm}^{2}\right)$ is exposed to the saline solution, areas of uniform corrosion and filiform corrosion have predominated. A few signs of localised corrosion have also been observed.

It is interesting to note the connection between the importance of localised corrosion and certain exposed area configurations of the tested specimens. With an exposed area of $\sim 0.5-0.8 \mathrm{~cm}^{2}$, limited by a circular gasket, the presence of abundant corrosion cavities has normally been observed, while on the specimens with an exposed area of $\sim 9-14 \mathrm{~cm}^{2}$ it has been usual to see the presence of clusters of filiform corrosion with hardly any sign of localised attack. 
A greater tendency towards the appearance of pits and cavities has been shown on polished AZ61 alloy than on polished AZ31 alloy surfaces, probably in consonance with the higher second phase particle content in the microstructure of the former.

According to the literature, filiform corrosion is assumed to proceed on magnesium alloys under a relatively resistant oxide film from points where this film is no longer continuous [11,12], and so the properties of the oxide film play a fundamental role in the development of enhanced filiform corrosion, probably via an electrolytic mechanism [13]. Figs. 6 and 7 show representative images of the filament clusters encountered on the specimens tested in this work. The proliferation of filament populations in regions close to the shear cut specimen edges is probably related with the high level of residual stresses in these regions; the tangled network of dislocations produced in the cold working process of cutting the metal plate must be a preferential site for attack initiation, with prevalence of the nucleation of filaments over other forms of corrosion.

The results of this research reveal a slightly lower tendency towards filiform corrosion on polished surfaces than on as-received surfaces, perhaps because polishing removes the original mill finished surface layer responsible for enhanced corrosion susceptibility $[14,15]$.

Another factor that may influence surface activity is the presence of aluminium in the oxide layer that coats the Mg-Al alloys. Many studies [16-23] mention the beneficial effect of aluminium, which can be en essential factor in determining the passivity of the surface, improving the resistance to local breakdown of the oxide and decreasing the chance of chloride ions penetrating to the surface. In 
the present work, this effect seems to be reflected in the corrosion of the polished AZ61 alloy specimens, where a large part of their surface retains for a quite some time the initial shine, while soon the polished surface of the AZ31 alloy, with a notably lower Al content, appears affected by the corrosion (Fig. 7).

\subsection{CORROSION RATE}

In parallel with the analysis of the influence of experimental variables on the attack morphology. It is also interesting to establish their impact, if any, on the corrosion rate, as well as to identify any possible relationship between these two different manifestations of the attack.

The chemical composition and the microstructure are well known to have significant effects on the corrosion rate of many metallic materials. In Mg-Al alloys these effects are related with the alloying aluminium concentration in whose structure it is found partly in solid solution in the a-matrix and partly precipitated as $\beta$-phase.

The surface oxide film on the specimens play a fundamental role in the corrosion rate. In tests carried out in $\mathrm{NaCl}$ solution, the quality of the surface film can be deteriorated if it is penetrated by the chloride ions. The addition of aluminium to magnesium modifies the composition and the structure of this film, improving its resistance to the aggressive attack of $\mathrm{Cl}^{-}$ions. In contrast with this beneficial action of aluminium, it is also necessary to taken into account the possibility that in certain circumstances a negative effect of $\mathrm{Al}$ on the corrosion of Mg-Al alloys can also be prevalent in the final result due to an enhanced microgalvanic action promoted by the $\beta$-phase [9]. 
If a significant improvement in the properties of the surface film is to be achieved, the bulk content of $\mathrm{Al}$ in the $\mathrm{Mg}-\mathrm{Al}$ alloys must exceed a certain critical level situated around $4 \%[20,22]$. The Al content is below this level in alloy AZ31 and above it in alloy AZ61. Therefore, an improvement in corrosion resistance due to the segregation of $\mathrm{Al}$ on the surface is only foreseeable in the latter alloy. Fig. 8 shows the intense attack of the AZ61 alloy with the surface in the as-received condition.

Tables 2-4 give values of the instantaneous corrosion rates evaluated from the slope of hydrogen evolution versus time curves, at the immersion times of 2, 4.5 and 10 days. These results refer to specimens immersed: vertically (Table 2); horizontally, with their top side exposed (Table 3 ); and placed horizontally, with the exposed area delimited by a circular gasket (Table 4). It is important to note the influence of the exposed area size and configuration on the variability of the results obtained. In the series of repeated tests, the lowest scatter has been obtained with square specimens exposing a surface area of $\sim 14 \mathrm{~cm}^{2}$ (Table 2), while the greatest specimen to specimen variability is found in the specimens with a small exposed area limited by a gasket (Table 4).

Referring principally to the data given in Tables 2 and 3 , in which the scatter is smaller, notable aspects include: (i) the marked reduction in the corrosion rate with immersion time for the AZ31-O and AZ31-P specimens; (ii) the less defined tendency for the corrosion rate to also decrease with immersion time for the AZ61-O specimens; and (iii) the reverse tendency of the AZ61-P specimens, which show increasing corrosion rates with immersion time. These tendencies are also reflected in Table 4, though less clearly due to the wide spread of the data. 
If the corrosion rate values determined after two hours of immersion are taken as a reference, little difference is seen between the data for AZ31-O, AZ31-P and AZ61-P specimens (Tables 2 and 3 ), but the difference is great when compared to the data for AZ61-O specimens, which show three or four times higher corrosion rates. This special behaviour may be explained taking into account the negative effect on the corrosion resistance of AZ61-O specimens of the presence of a not very compact, and little protective, oxide film in the asreceived condition, and the accelerated micro-galvanic corrosion due to the significant $\beta$-phase fraction in the AZ61 alloy.

In the initial phase of the immersion test attention is drawn to the notably lower corrosion rate on the polished AZ61 specimens compared to the specimens of the same alloy in the as-received surface condition. The difference may be due to the strong protective effect of the oxide film that forms spontaneously on the polished AZ61 alloy surface, which is much more perfect and protective than the film on the as-received surface (formed during sheet production). As long as these properties do not noticeably deteriorate with testing time, said film will prevent or slow micro-galvanic corrosion on the AZ61-P specimens.

The reduction in the corrosion rate of the AZ31 alloy specimens with immersion time up to the 10 days duration of the test (Tables 2 and 3) suggests a progressive accumulation of corrosion products on the metallic surface, phenomenon not perceived by simple macroscopic observation. The corrosion rate also tends to decrease on the AZ61 alloy specimens in as-received condition, but much more slowly than on the AZ31 alloy specimens, perhaps because the effect of the accumulation of corrosion products is now partly 
countered by the effect of micro-galvanic corrosion present on the two-phase AZ61 alloy.

The fact that the corrosion rate on the AZ61-P specimens grows during the 10 days of testing (Tables 2 and 3 ) suggests the idea of progressive deterioration due to the action of $\mathrm{Cl}^{-}$ions in the protective film that initially coats the polished surface of this alloy.

On the basis of the experimental results described in this paper it is not possible to speak of any regular interrelation between the macroscopic morphology of the corroded surfaces and corrosion rate. In general, the factors determining the different rates of corrosion and their changes with immersion time are not related with the morphological changes observed at macroscopic scale, probably because the true relations are rather with structural features discernible only at micro- or submicroscopic scale.

\section{CONCLUSIONS}

1. The study of the effect of experimental variables on the morphology of attack on $\mathrm{AZ31}$ and $\mathrm{AZ61}$ magnesium alloys in $\mathrm{NaCl}$ solution has revealed the possibility of a notable effect of the exposed area size and configuration. The initial surface condition of the specimens has also been seen to exert a certain influence on the results obtained, with a moderate tendency for corrosion resistance to improve on polished surfaces compared to as-received surfaces.

2. The morphology of the corroded surfaces has been predominated by areas of uniform corrosion and filiform corrosion. In contrast, few signs of localised 
corrosion have been seen on most of the examined specimens. The occurrence of localised corrosion has shown a dependence on the configuration of the exposed surface; small pits and other forms of localised corrosion have been found on specimens with an exposed area (delimited by a circular gasket) of $0.5-0.8 \mathrm{~cm}^{2}$, upon which filiform corrosion was, however, virtually absent.

3. Square coupon specimens with shear cut edges, whose entire surface area of $\sim 9-14 \mathrm{~cm}^{2}$ was exposed to the aggressive solution, have shown great susceptibility to the development of filament populations in regions close to the cut edges.

4. A special feature of the AZ61 alloy specimens in as-received surface condition is that they showed corrosion rates three or four times higher than the other tested specimens, a phenomenon that is explained by the combination of a poorly protective oxide film on the as-received surface and an accelerated micro-galvanic effect on this alloy. In contrast, the notably lower corrosion rate on the polished surface condition may be attributed to the special protective effect of the continuous oxide film that tends to spontaneously form on the smooth surface of the AZ61 alloy.

5. On a macroscopic scale, no clear relationship between attack morphology and corrosion rate has been observed, probably due to the micro- or submicroscopic nature of the structural features that affect the various corrosion mechanisms. 


\section{Acknowledgments}

We wish to express our gratitude to Professor S. Feliu for several clarifying and stimulating discussions during the course of this work. The authors also gratefully acknowledge the financial support for this work from the Spanish Ministry of Science and Innovation (MAT 2009-13530) 


\section{REFERENCES}

[1] Z.M. Shi, M. Liu, A. Atrens, Measurement of the corrosion rate of magnesium alloys using Tafel extrapolation, Corros. Sci. 52 (2010) 579-588.

[2] S. Feliu Jr., C. Maffiotte, J.C. Galván, V. Barranco, Atmospheric corrosion of magnesium alloys AZ31 and AZ61 under continuous condensation conditions, Corros Sci. 53 (2011) 1865-1872.

[3] S. Feliu Jr., C. Maffiotte, A. Samaniego, J.C. Galván, V. Barranco, Effect of naturally formed oxide films and other variables in the early stages of Mg-alloys in $\mathrm{NaCl}$ solution, Electrochim. Acta 56 (2011) 4554-4565.

[4] M. Kühlein, U. Galovsky, Influence of testing parameters on the corrosion rate of magnesium alloys, Materials and Corrosion, 55 (2004) 444-448.

[5] G. Song, Z. Xu, The surface, microstructure and corrosion of magnesium alloy AZ31 sheet, Electrochim. Acta, 55 (2010) 4148-4161.

[6] M. Zidoune, M.-H. Grosjean, L. Roué, J. Huot, R. Schulz, Comparative study on the corrosion behavior of milled and unmilled magnesium by electrochemical impedance spectroscopy, Corros. Sci. 46 (2004) 3041-3055.

[7] Z.M. Shi, A. Atrens, An innovative specimen configuration for the study of Mg corrosion, Corros. Sci. 53 (2011) 226-246.

[8] R.L. Xin, B. Li, Q. Liu, Influence of texture on corrosion rate of AZ31 Mg alloy in 3.5 wt\% NaCl, Mater. Design., 32 (2011) 4548-4552. 
[9] G.L. Song, A. Atrens, Understanding magnesium corrosion - A framework for improved alloy performance, Advanced Engineering Materials 5 (2003) 837858.

[10] M. Liu, P. Schmutz, P.J Uggowitzer, G.L. Song, A Atrens, The influence of yttrium (Y) on the corrosion of Mg-Y binary alloys, Corros. Sci. 52 (2010) 36873701.

[11] O. Lunder, J.E. Lein, S.M. Hesjevic, T.K. Aune, K. Nisancioglu, Corrosion morphologies on magnesium alloy AZ-91, Werkst. Korros. 45 (1994) 331-340.

[12] P. Schmutz, V. Guillaumin, R.S. Lillard, J.A. Lilard, G.S. Frankel, Influence of dichromate ions on corrosion processes on pure magnesium, J. Electrochem. Soc., 150 (2003) B99-B110.

[13] G. Williams, R. Grace, Chloride-induced filiform corrosion of organic-coated magnesium, Electrochim. Acta, 56 (2011) 1894-1903.

[14] A.J. Kayes, M.J. Robinson, S. Impey, The influence of cleaning and surface treatment on filiform corrosion of aluminium alloys, JCSE (The journal of Corrosion Science and Engineering) Vol. 2, paper 1, published $12^{\text {th }}$ November 1999.

[15] P. Premendra, W. Loven, H. Terrin, J.H.W. deWit, L. Katgerman, Consequences of hot rolling of recycled AA5050 on filiform corrosion, Material Science Forum, Vols. 519-521 (2006) 687-692.

[16]. G.L. Song, A. Atrens, Corrosion mechanisms of magnesium alloys, Adv. Eng. Mater. 1 (1999) 11-33. 
[17] R. Lindstrom, J.E. Svensson, L.G. Johansson, The influence of carbon dioxide on the atmospheric corrosion of some magnesium alloys in the presence of $\mathrm{NaCl}$, J. Electrochem. Soc. 149 (2002) B103-B107.

[18] S. Feliu Jr., M.C. Merino, R. Arrabal, A.E. Coy, E. Matykina, XPS study of the effect of aluminium on the atmospheric corrosion of the AZ31 magnesium alloy, Surf. Interface Anal. 41 (2009) 143-150.

[19] M. Liu, P.J. Uggowitzer, A.V. Nagasekhar, P. Schmutz, M. Easton, G.L. Song, A. Atrens, Calculated phase diagrams and the corrosion of die-cast MgAl alloys, Corros. Sci. 51 (2009) 602-619.

[20] J.H. Nordlien, K. Nisancioglu, S. Ono, N. Masuko, Morphology and structure of oxide films formed on MgAl alloys by exposure to air and water, J. Electrochem. Soc. 143 (1996) 2564-2572.

[21] A. Pardo, M.C. Merino, A.E. Coy, R. Arrabal, F. Viejo, E. Matykina, Corrosion behaviour of magnesium/aluminium alloys in $3.5 \mathrm{wt} \% \mathrm{NaCl}$, Corros. Sci. 50 (2008) 823-834.

[22] M. Jönsson, D. Persson, R. Gubner, The initial steps of atmospheric corrosion on magnesium alloy AZ91D, J. Electrochem. Soc., 154 (2007) C 684C691.

[23] N. Hara, Y. Kobayashi, D. Kagaya, N. Akao, Formation and breakdown of Surface films on magnesium and its alloys in aqueous solutions, Corros. Sci., 49 (2007) 166-175. 


\section{FIGURE CAPTIONS}

Fig. 1. Detail of the joint between square test specimen and cylindrical cell limiting the exposed area.

Fig. 2. Presence of sub-micron pits on the corroded surface of the tested specimen.

Fig. 3. Holes of localised attack (dark spots) distributed on the filament grooves left by filiform corrosion after the removal of corrosion products.

Fig. 4. Pits and open cavities on the exposed circular area.

Fig. 5. Uniform attack with some signs of filiform corrosion close to the drilled hole.

Fig. 6. Extensive areas of filiform corrosion.

Fig. 7. Photographic images of the evolution of corrosion morphology with immersion time for alloys AZ31 and AZ61 in the as-received (O) and polished (P) surface conditions.

Fig. 8. Intense attack of the AZ61 alloy surface exposed in the as-received condition. 
Table 1. Chemical composition of AZ31 and AZ61 alloys (wt. \%).

$\begin{array}{lccccccc}\text { Alloy } & \mathrm{Al} & \mathrm{Zn} & \mathrm{Mn} & \mathrm{Si} & \mathrm{Fe} & \mathrm{Ca} & \mathrm{Mg} \\ \text { AZ31 } & 3.1 & 0.73 & 0.25 & 0.02 & 0.005 & 0.0014 & \text { Bal. } \\ \text { AZ61 } & 6.2 & 0.74 & 0.23 & 0.04 & 0.004 & 0.0013 & \text { Bal. }\end{array}$




\section{Table 2}

Instantaneous corrosion rates $(\mathrm{mg} / \mathrm{cm} 2 / \mathrm{d})$ for different immersion times. Square specimens placed vertically exposing the entire surface.

(AZ31 and AZ61 specimens in the original $(\mathrm{O})$ and polished $(\mathrm{P})$ surface conditions)

\begin{tabular}{cccc}
\hline \multicolumn{4}{c}{ AZ31-O } \\
\hline Specimen & 2 days & 4.5 days & 14 days \\
\hline $\mathrm{a}-1$ & 0.60 & 0.24 & 0.21 \\
$\mathrm{a}-2$ & 0.55 & 0.22 & 0.18 \\
$\mathrm{a}-3$ & 0.55 & 0.28 & 0.23 \\
$\mathrm{a}-4$ & 0.43 & 0.26 & - \\
\hline \multicolumn{5}{c}{} \\
\hline \multicolumn{5}{c}{ AZ31-P } \\
\hline Specimen & 2 days & 4.5 days & 14 days \\
\hline b-1 & 0.42 & 0.27 & 0.16 \\
b-2 & 0.39 & 0.25 & 0.15 \\
b-3 & 0.55 & 0.26 & 0.14 \\
b-4 & 0.37 & 0.18 & - \\
\hline
\end{tabular}

\begin{tabular}{cccc}
\hline \multicolumn{4}{c}{ AZ61-O } \\
\hline Specimen & 2 days & 4.5 days & 14 days \\
\hline c-1 & 2.57 & 2.39 & 2.00 \\
c-2 & 2.94 & 2.58 & 2.10 \\
c-3 & 2.39 & 2.40 & - \\
c-4 & 2.48 & 2.21 & - \\
\hline \multicolumn{5}{c}{ AZ61-P } \\
\hline \multicolumn{5}{c}{} \\
\hline Specimen & 2 days & 4.5 days & 14 days \\
\hline d-1 & 0.30 & 0.45 & 0.58 \\
d-2 & 0.51 & 0.63 & 1.40 \\
d-3 & 0.46 & 0.64 & 2.25 \\
d-4 & 0.41 & 0.49 & 0.56 \\
d-5 & 0.45 & 0.57 & - \\
\hline
\end{tabular}




\section{Table 3}

Instantaneous corrosion rates $(\mathrm{mg} / \mathrm{cm} 2 / \mathrm{d})$ for different immersion times. Square specimens placed horizontally, exposing only the upper face.

(AZ31 and AZ61 specimens in the original $(\mathrm{O})$ and polished $(\mathrm{P})$ conditions)

\begin{tabular}{cccc}
\hline \multicolumn{4}{c}{ AZ31-O } \\
\hline Specimen & 2 days & 4.5 days & 14 days \\
\hline e-1 & 0.54 & 0.30 & 0.18 \\
e-2 & 0.39 & 0.26 & 0.12 \\
e-3 & 0.32 & 0.15 & 0.13 \\
\hline
\end{tabular}

\begin{tabular}{cccc}
\hline Specimen & 2 days & 4.5 days & 14 days \\
\hline $\mathrm{g}-1$ & 2.40 & 2.78 & 2.60 \\
$\mathrm{~g}-2$ & 2.00 & 2.22 & 1.95 \\
$\mathrm{~g}-3$ & 0.73 & 0.76 & 0.75 \\
\hline
\end{tabular}

AZ31-P

\begin{tabular}{cccc}
\hline Specimen & 2 days & 4.5 days & 14 days \\
\hline$f-1$ & 0.35 & 0.23 & 0.19 \\
$f-2$ & 0.39 & 0.25 & 0.09 \\
$f-3$ & 0.27 & 0.13 & 0.07 \\
\hline
\end{tabular}

\begin{tabular}{cccc}
\hline \multicolumn{4}{c}{ AZ61-P } \\
\hline Specimen & 2 days & 4.5 days & 14 days \\
\hline h-1 & 0.42 & 0.60 & 0.72 \\
h-2 & 0.39 & 0.41 & 0.51 \\
h-3 & 0.30 & 0.40 & 0.43 \\
\hline
\end{tabular}


Table 4. Instantaneous corrosion rates $(\mathrm{mg} / \mathrm{cm} 2 / \mathrm{d})$ for different immersion times . Exposed area delimitated by a circular gasket on the specimens placed horizontally.

(AZ31 and AZ61 specimens in the original $(\mathrm{O})$ and polished $(\mathrm{P})$ surface conditions)

\begin{tabular}{ccc}
\hline \multicolumn{3}{c}{ AZ31-O } \\
\hline Specimen & 2 days & 4.5 days \\
\hline $\mathrm{i}-1$ & 1.44 & 1.10 \\
$\mathrm{i}-2$ & 1.25 & 0.72 \\
$\mathrm{i}-3$ & 14.4 & 9.16 \\
$\mathrm{i}-4$ & 6.24 & 4.40 \\
$\mathrm{i}-5$ & 2.62 & 1.05 \\
$\mathrm{i}-6$ & 0.20 & 0.25 \\
$\mathrm{i}-7$ & 0.87 & - \\
$\mathrm{i}-8$ & 1.80 & - \\
\hline
\end{tabular}

\begin{tabular}{ccc}
\hline \multicolumn{3}{c}{ AZ61-O } \\
\hline Specimen & 2 days & 4.5 days \\
\hline k-1 & 0.96 & 0.90 \\
k-2 & 0.22 & 0.13 \\
k-3 & 2.97 & 3.20 \\
k-4 & 0.50 & 0.35 \\
k-5 & 4.61 & - \\
k-6 & 0.96 & - \\
k-7 & 4.76 & 5.81 \\
k-8 & 2.50 & 2.50 \\
\hline
\end{tabular}

\begin{tabular}{ccc}
\hline \multicolumn{3}{c}{ AZ31-P } \\
\hline Specimen & 2 days & 4.5 days \\
\hline $\mathrm{j}-1$ & 0.65 & 0.27 \\
$\mathrm{j}-2$ & 0.57 & 0.20 \\
$\mathrm{j}-3$ & 8.07 & 8.45 \\
$\mathrm{j}-4$ & 0.42 & - \\
$\mathrm{j}-5$ & 0.40 & - \\
\hline
\end{tabular}

\begin{tabular}{ccc}
\hline \multicolumn{3}{c}{ AZ61-P } \\
\hline Specimen & 2 days & 4.5 days \\
\hline $\mathrm{I}-1$ & 0.50 & 0.56 \\
$\mathrm{I}-2$ & 0.41 & 0.44 \\
$\mathrm{I}-3$ & 0.33 & - \\
$\mathrm{I}-4$ & 0.14 & - \\
\hline
\end{tabular}




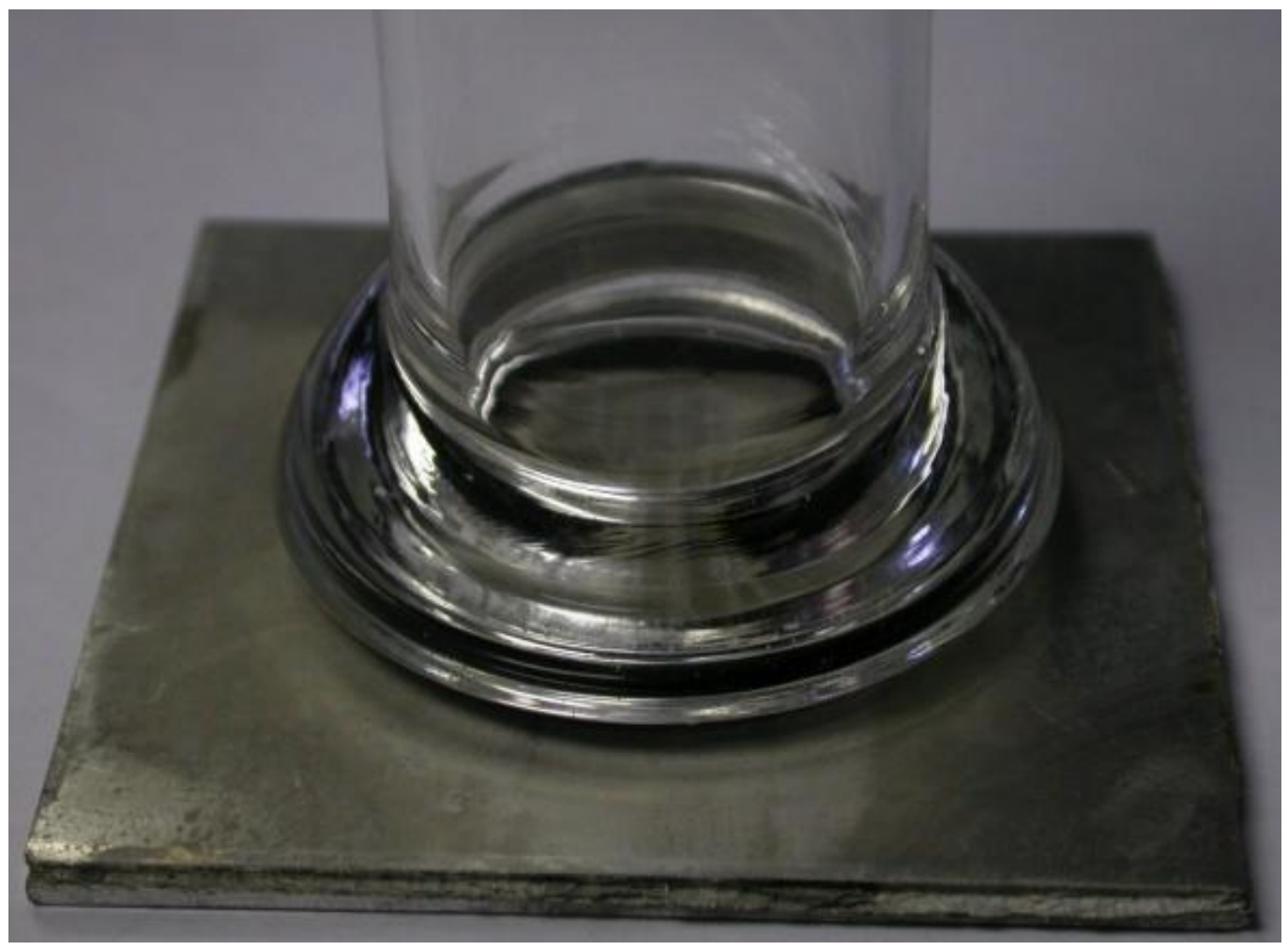

Figure 1. 


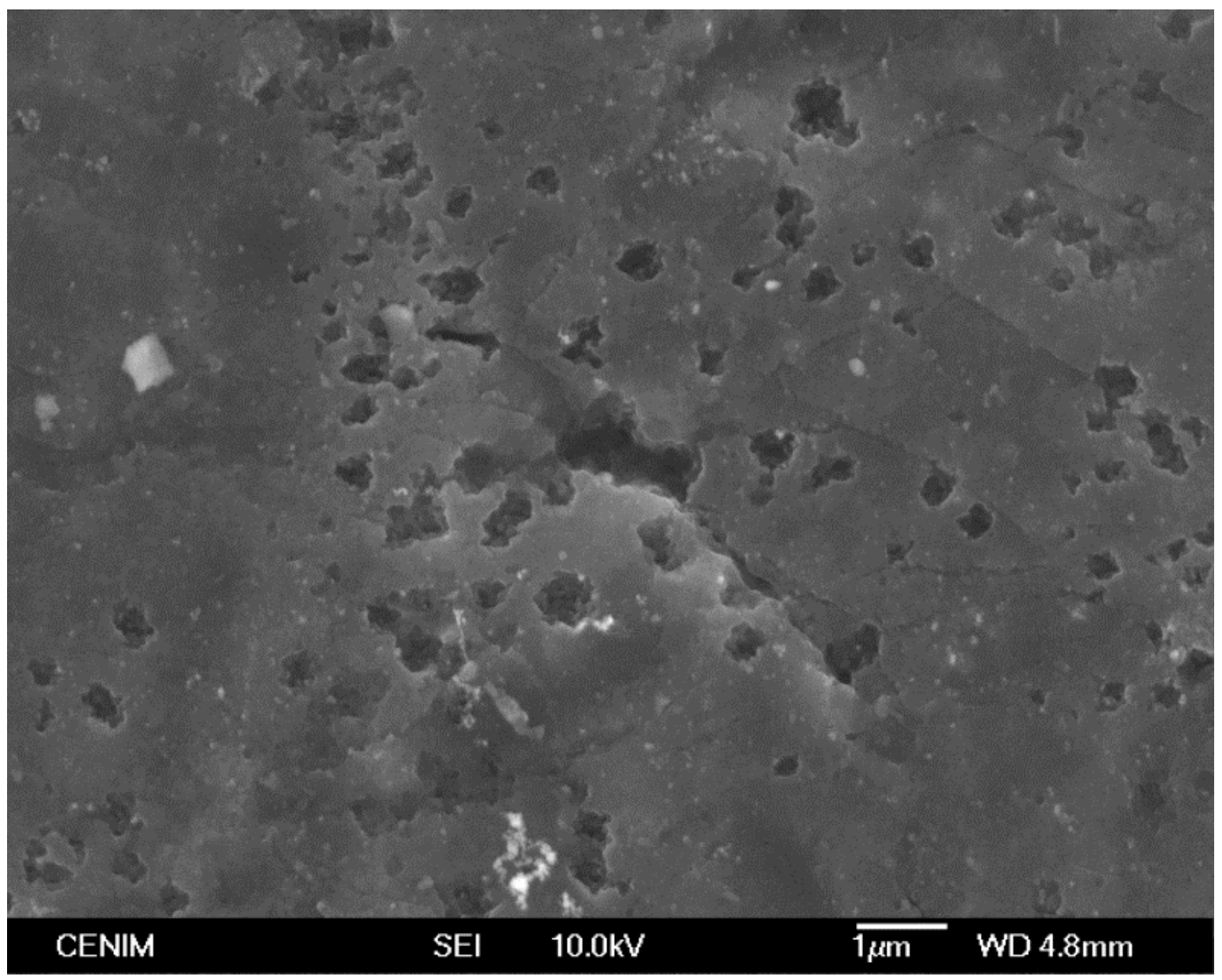

Figure 2 


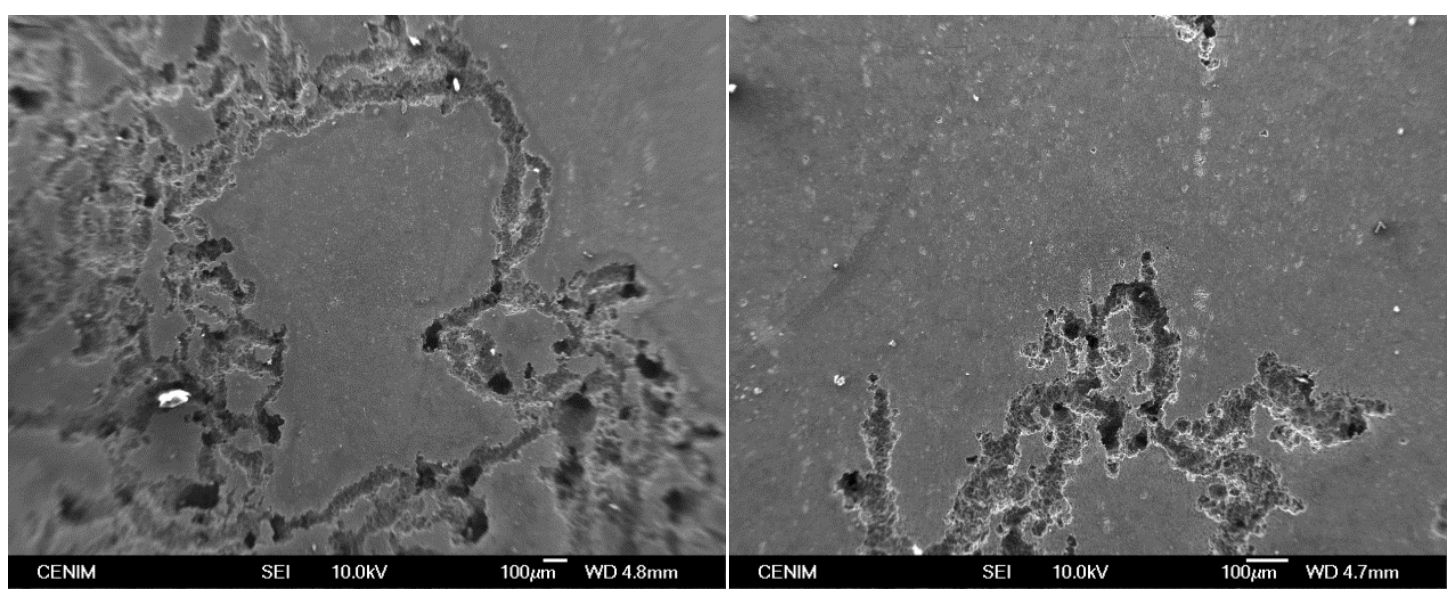

Figure 3 


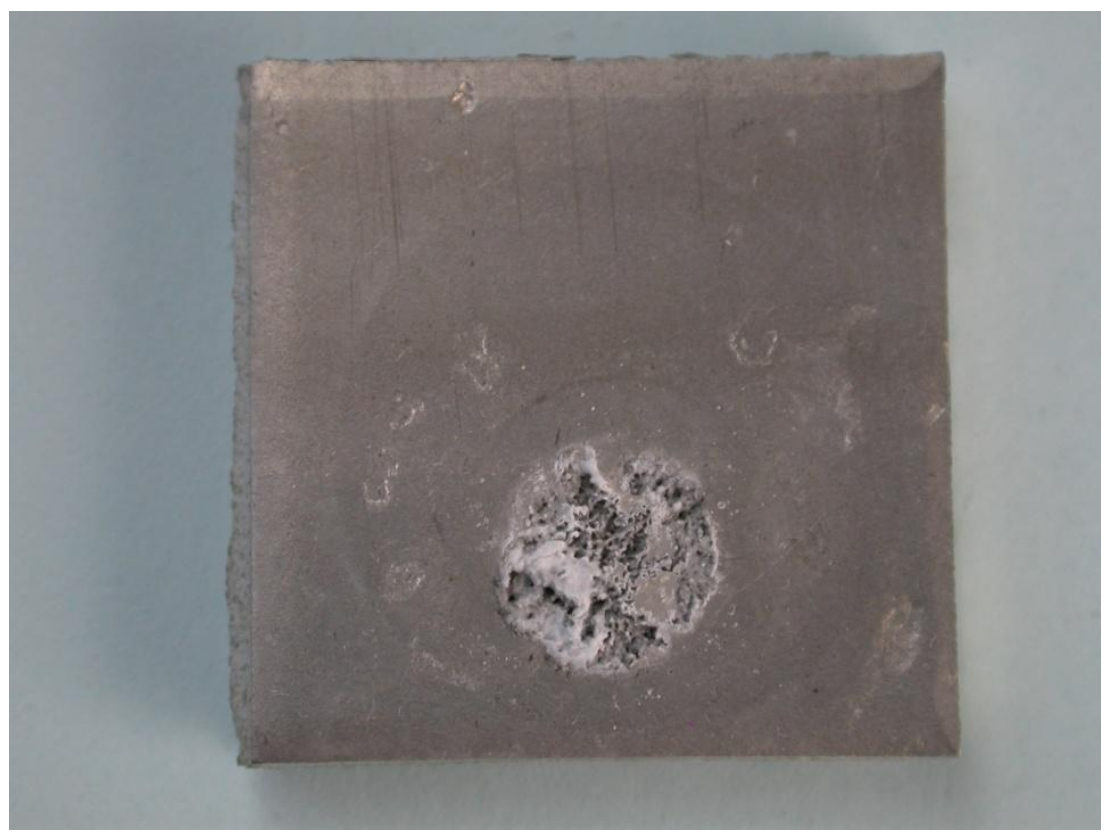

Figure 4 


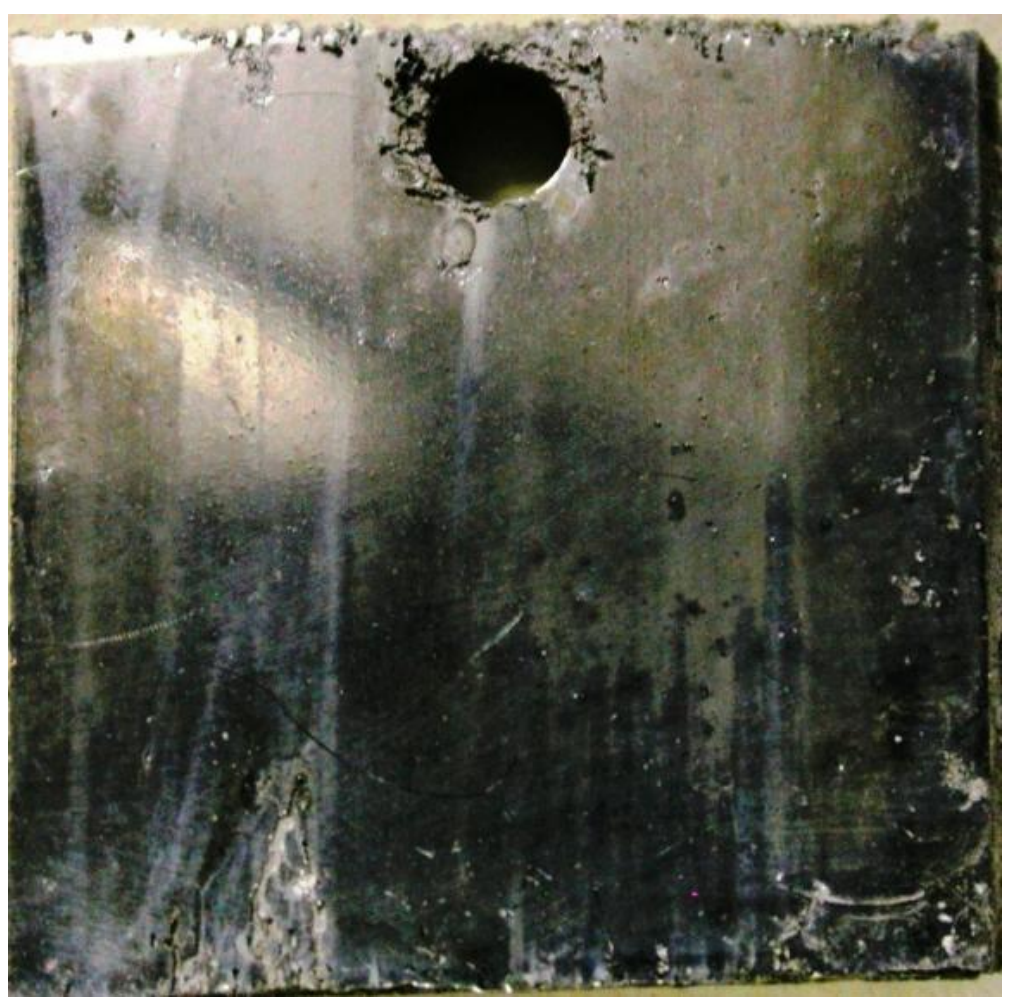

Figure 5. 


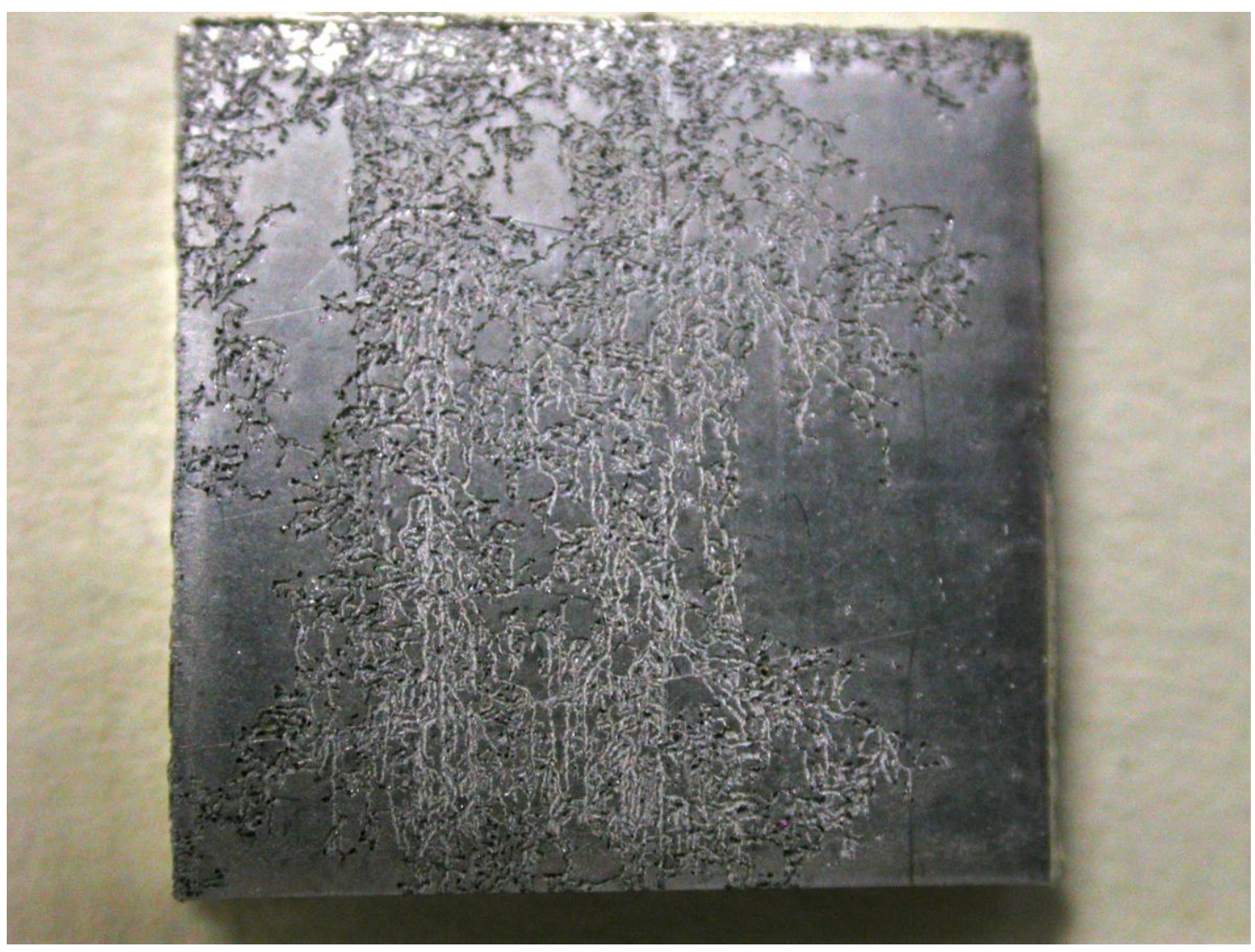

Figure.6 


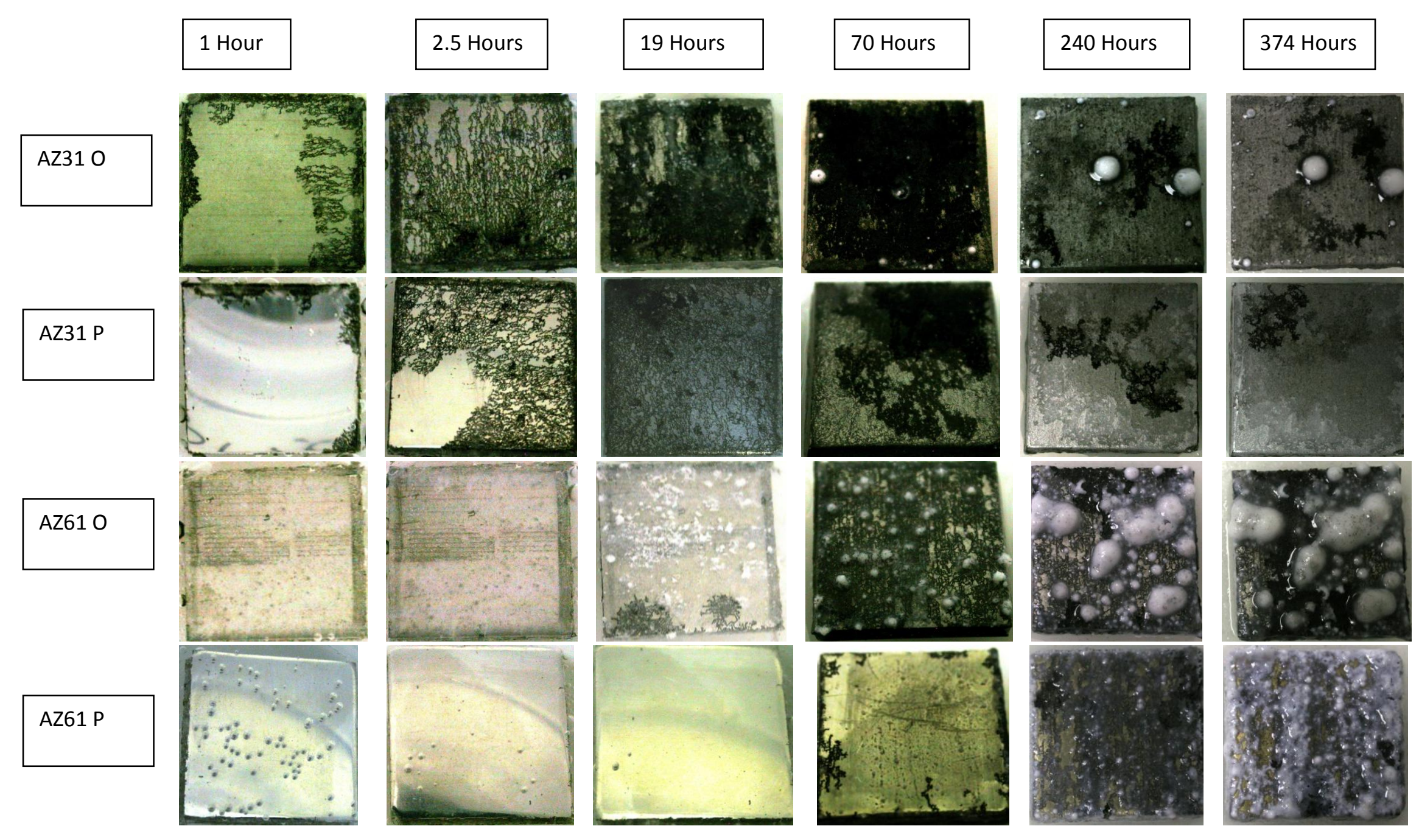

Figure.7 


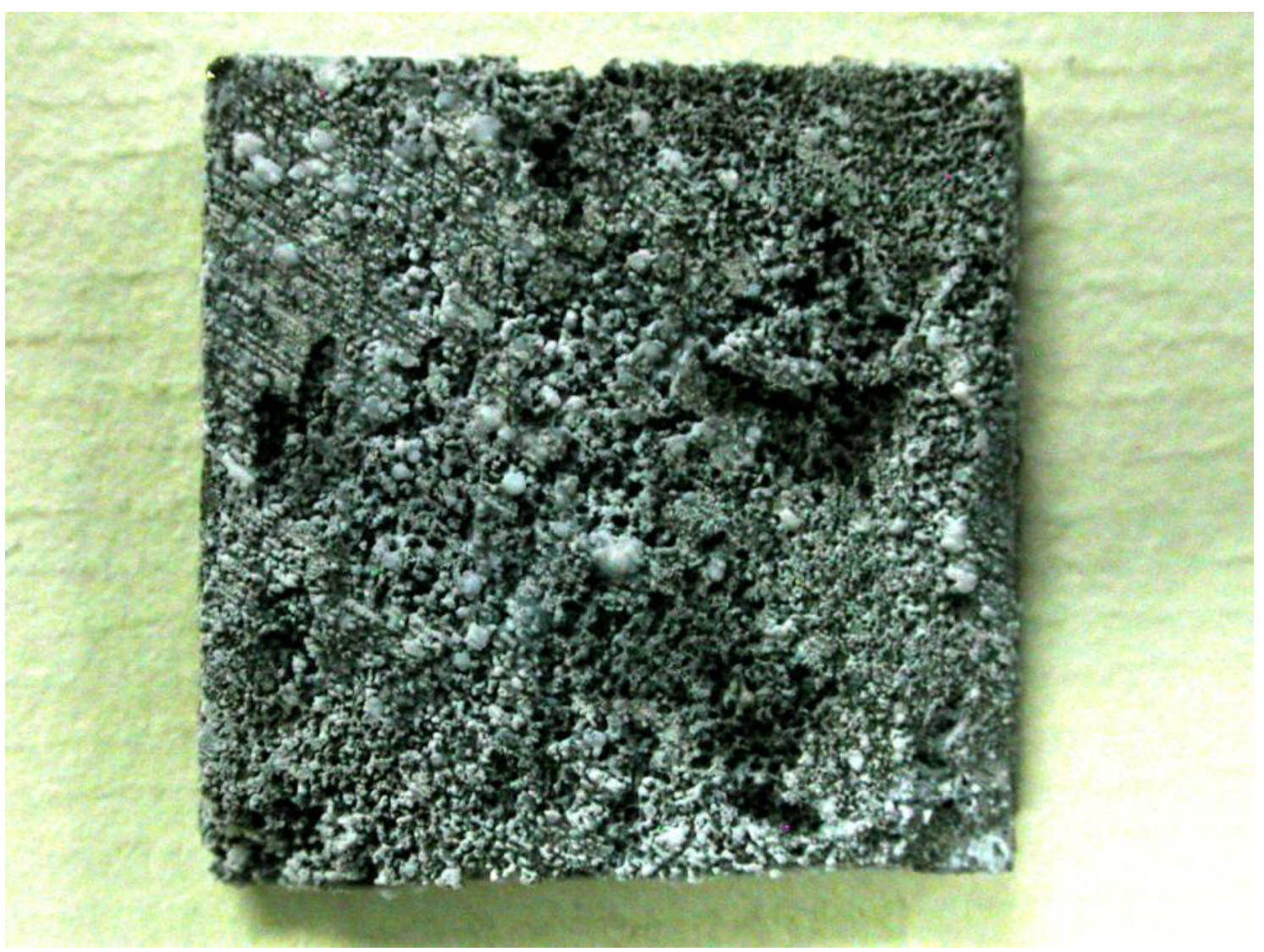

Figure 8. 